\title{
Endogenous social discount rate, proportional carbon tax, and sustainability: Do we have the right to discount future generations' utility?
}

\author{
Masayuki Otaki
}

\begin{abstract}
Background: This paper examines a serious issue - whether future generations of utility should be discounted. The issue is of vital importance because future generations will never have the opportunity to reveal their preference regarding the current resource allocation and yet this will ultimately affect their utility. This paper addresses with this issue in the context of the phenomenon of global warming that is crucially connected with the emission and accumulation of $\mathrm{CO}_{2}$.

Results: The analysis focuses on how the social optimum is attained under the constraint of sustainability and reveals the following relationship between the optimal policies: not discounting utility in social planning corresponds to adopting the socially optimal carbon tax rate in a decentralized economy.

We also prove that the optimal carbon tax regime satisfies time consistency, indicating that policy is Pareto efficient for every generation given the sustainability constraint. In addition, it is shown that the theory can be extended to apply to an infinite horizon.

Finally, the second-best proportional carbon tax rates are calculated using available data. The result astonishingly reveals that even if we apply a social discount rate of 5 per cent to annum in the planning economy, it is still equivalent to levying 32 per cent proportional carbon tax rate.
\end{abstract}

Conclusions: Considering the actual absorption capacity of oceans concerning $\mathrm{CO}_{2}$, we can never be too prudent in discounting the utility of future generations with regard global climate change. This fact indicates the need for urgent introduction of a proportional carbon tax.

Keywords: Endogenous social discount rate, Proportional carbon tax, Ordinal utilitarian, Sustainability, Time consistency

\section{Background}

Evaluation of future generations' utility is a difficult issue, as they cannot question their ancestors' behavior. In other words, the economic activity of the current generation affects voiceless future generations. The most prominent example of such a problem is global warming which is inseparable from the emission and accumulation of $\mathrm{CO}_{2}$.

There is a huge volume of research accumulation that concerns the relationship between the concentration of $\mathrm{CO}_{2}$ and global warming. Hulme (2009, Ch.2) concisely reviews theory of the anthropogenic climate change that

Correspondence: ohtaki@iss.u-tokyo.ac.jp

Institute of Social Science, University of Tokyo, 7-3-1 Hongo, Bunkyo, Tokyo, Japan

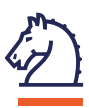

Springer

(c) 2013 Otaki; licensee Springer. This is an Open Access article distributed under the terms of the Creative Commons Attribution License (http://creativecommons.org/licenses/by/2.0), which permits unrestricted use, distribution, and reproduction in any medium, provided the original work is properly cited. originates from Tyndal's experiment in 1859. Calendar (1938) estimated that the global temperature would rise at the rate of $0.3^{\circ} \mathrm{C}$ per century. On the other hand, Keeling's measurements at the South Pole (from 1957) and Mt. Mauna Loa (from 1958) revealed that the $\mathrm{CO}_{2}$ concentration was rising by 0.5 to $1.3 \mathrm{ppm}$ per year at both sites.

According to Pearson (2000, p.385), there is evidence that the $\mathrm{CO}_{2}$ concentration leads to the global warming. Pearson and Pryor (1994) found that the $\mathrm{CO}_{2}$ concentration increases from 315ppm to 331ppm between 1958 and 1975, furthermore, their observations revealed that concentrations would reach $358 \mathrm{ppm}$ by 1994 . On the other hand, the concentration during the preindustrial era is estimated at $280 \mathrm{ppm}$. The global average temperature increased between $0.5-1.7^{\circ} \mathrm{F}$. Ramanathan et al. (1985) 
estimated that the surface temperature will rise within $1.5-2.5^{\circ} \mathrm{K}$ from 1980 to $2030\left(0.5-1.7^{\circ} \mathrm{F}\right)$. In addition, Houghton et al. (1996) estimated that due to a discernible human influence on the global climate, temperature will increase by $1.1-3.3^{\circ} \mathrm{K}\left(2-6^{\circ} \mathrm{F}\right)$ over the next 100 years. Uzawa (2003, pp.1-21) gives a precise survey of more specialized articles concerning global warming as it relates to economic theory.

Much research within resource and environmental economics discounts the utility of future generations a priori. ${ }^{a}$ However, no solid logical foundation is given for the reason permitting such discounting. As such, the main purpose of this article is to determine endogenously the optimal discount rate incurred in the $\mathrm{CO}_{2}$ emission/ accumulation problem based on ordinal utility. We solve the problem using the constraint of "sustainability" proposed by Pezzey (1997) in a planning economy.

As Dasgupta (2008) summarizes, whether discounting is permitted is can be attributed to the problem of "ethics". In this context, "ethics" indicates a method that introduces additional, exogenous, and stronger axioms concerning the comparison of utility streams. Koopmans (1960) classifies the case in which discounting is permitted. Diamond (1965) explains that no utility-discounting leads to a contradiction when some assumptions are imposed in addition to plausible standards of utilitystream comparison. Both studies negate the possibility of non-discounting.

On the other hand, Cowen (1992) and Blackorby et al. (1995) assume cardinal utility, in which utilities are comparable between individuals, and insist that discounting is not permissible. However, the cardinality of individual utility is quite a strong assumption regarding the current welfare economics criterion.

Although arriving at opposite conclusions, such studies have common characteristics. That is, in addition to the usual assumptions concerning the utility function of each generation, they all give exogenous and restrictive value judgments in attaining their results.

This article is based on a solely ordinal utilitarian definition of sustainability proposed by Pezzey (1997). That is, we call an economy sustainable when each generation $j$ can enjoy the minimal utility level $\bar{U}$. ${ }^{\text {b }}$ By using ordinal utility, we entirely exclude any exogenous and transcendent utility comparisons between generations. Such a broad value judgment is not adopted in the preceding research.

This paper determines the optimal social discount rate using the steps outlined below, while avoiding Dasgupta's "ethical" problem. That is, while never imposing any additional restrictions on individuals' ordinal utility function, we arrive at the optimal discount rate using the following two steps.

As the first-best benchmark case, we calculate the optimal tax that is proportional to emissions of $\mathrm{CO}_{2}$, based on the given definition of sustainability. Since, for simplicity, we assume that current generations are not concerned with the utility of generations thereafter, and only a part of $\mathrm{CO}_{2}$ emission is absorbed by oceans, biomass, and etc., new emissions will accumulate in the future. A proportional carbon tax is desirable because the tax fully reflect the true price of $\mathrm{CO}_{2}$, and thus the price mechanism use to deter excess emissions. In other words, when a higher tax is incurred by the $\mathrm{CO}_{2}$ emissions, individuals reduce their emissions, which consequently reduce $\mathrm{CO}_{2}$ carried over to future generations.

Second, we solve the social planning problem to attain the same utility level as that which occurs under the optimal proportional carbon tax (the first-best solution). This procedure, also known as the method of Negishi (1960), reveals the relation between the optimal carbon tax rate in a market economy and the endogenously determined social discount rate in a planning economy.

This gives the result that conventional discounting in social planning cannot achieve the optimal taxation in a market economy, if each generation has a right to enjoy some fixed utility, utility should be equally weighed. ${ }^{\mathrm{c}}$

It is noteworthy that utility discounting is compatible with our ordinal utilitarian definition of sustainability. A positive discount rate in the economy implies that every generation prefers more consumption to the amenity acquired from a reduction in $\mathrm{CO}_{2}$ emissions. As such, even in the stationary state, the economy will not necessarily reach the first-best resource allocation. Thus, the optimal social discount rate is not self-evident, even with the ordinal utilitarian view of sustainability in stationary state.

\section{Results and Discussion \\ The Model \\ Dynamics of $\mathrm{CO}_{2}$}

We assume the dynamics of $\mathrm{CO}_{2}$ accumulation is as follows:

$$
e_{t}=\alpha e_{t-1}+c_{t}, \quad 0<\alpha<1
$$

where $e_{t}$ is the stock of $\mathrm{CO}_{2}$ measured by its weight, $c_{t}$ is current consumption, and $\alpha$ denotes the proportion of $\mathrm{CO}_{2}$ remaining per period. We further assume that a unit production/consumption emits a unit weight $\mathrm{CO}_{2}$. This assumption is permitted by defining the unit of production/consumption volume so as to correspond to the unit weight emission of $\mathrm{CO}_{2}$.

The economic meaning of equation (1) is as follows: The sum of $\mathrm{CO}_{2}$ that remains within the atmosphere at the end of period $t$ consists of $\mathrm{CO}_{2}$ carried over from the previous period, which was not absorbed by oceans, forests, and etc., that is, $\alpha e_{t-1}$, and the newly emitted $\mathrm{CO}_{2}$ by generation $t$ 's economic activity, that is, $c_{t}$. Note that although the linear relationship in (1) seems to be 
oversimplified, it is not difficult to extend to the nonlinear feasible set as long as the set is strictly convex by using the separation theorem of convex sets (see Figure 1). Nevertheless, in such a case, it becomes necessary to have information concerning the utility function to determine the stationary state in which the highest utility is attained.

Another way to consider the difference equation (1) is as follows: The current total $\mathrm{CO}_{2}$ stock $e_{t}$ consists of two parts. One is the accumulated stock of $\mathrm{CO}_{2}$ carried over from the previous period $\alpha e_{t-1}$. The other is the flow emitted due to current-period consumption $c_{t}$. Thus, the dimension of equation (1) is the weight of $\mathrm{CO}_{2}$ (giga-ton).

Takahashi et al. (1980) estimate that the portion of remaining $\mathrm{CO}_{2}, \alpha$ is approximately $40 \%$ per annum although this dissociation rate is very sensitive to the depth, temperature, salinity, and alkalinity of oceans, etc.. ${ }^{\mathrm{d}}$

\section{Individuals}

Individuals live for one period. Their identical, strictly concave, utility function $U_{t}$ is as follows:

$$
U_{t} \equiv u\left(c_{t}, e_{t}\right), \quad \frac{\partial u}{\partial c_{t}}>0, \frac{\partial u}{\partial e_{t}}<0 .
$$

The individuals' feasibility constraint is

$$
e_{t}=\alpha e_{t-1}+[1+\theta] c_{t}-\tau_{t},
$$

where $\theta$ denotes the proportional carbon tax rate and $\tau_{t}$ is a transfer from the government.

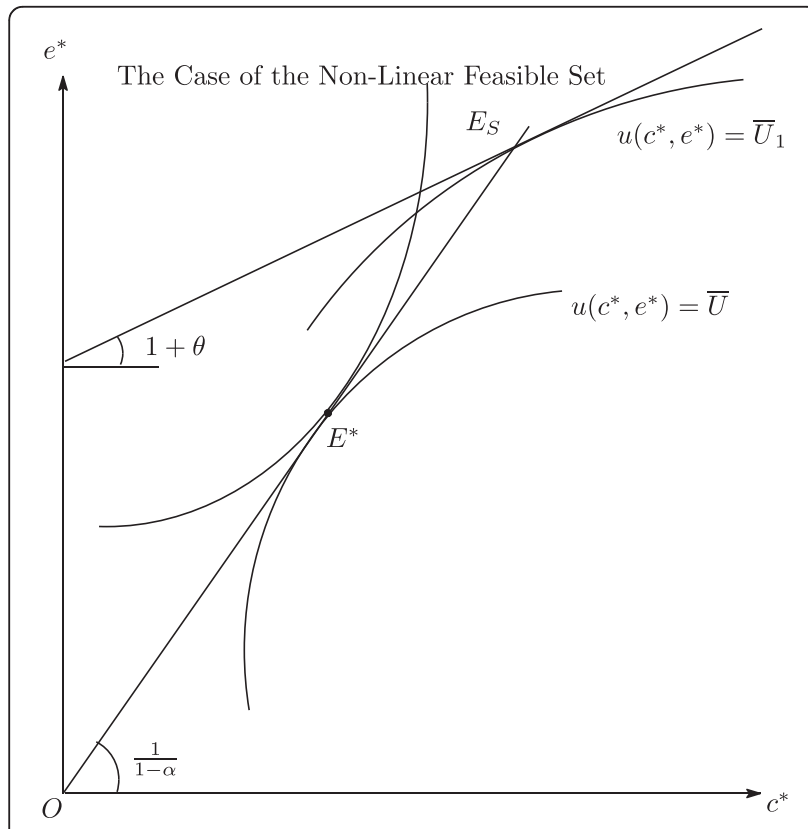

Figure 1 Pareto Optimality and Carbon Tax.
The meaning of (3) is as follows: Since $\theta$ additional units of the consumption good are necessary due to the carbon tax incurred, the effective price of the consumption $\operatorname{good} / \mathrm{CO}_{2}$ price becomes $1+\theta$, as in the second term of (3) (note that from (1), a unit of consumption is assumed to emit a unit of $\left.\mathrm{CO}_{2}\right)$. On the other hand, the transfer from the government reduces the production and mitigates emissions. This is why $\tau_{t}$ has a negative sign in the right-hand side of (3). It reduces to the difference equation (1) that represents the dynamic of $\mathrm{CO}_{2}$ accumulation, if we take the budget constraint of the government.

\section{Government}

The government transfers the collected tax to individuals equally. ${ }^{\mathrm{e}}$ Namely, the budget constraint of the government is as follows:

$$
\theta c_{t}=\tau_{t}
$$

\section{Market economy and social planning}

In this section, we first solve for the optimal carbon tax rate in a stationary market economy. Second, we consider the optimal social planning regarding $\mathrm{CO}_{2}$ emission that has the same effect as the optimal proportional carbon tax. Based on these considerations, we answer the question of whether the utility of future generations should be discounted in a planning economy.

\section{Optimal tax rate in a stationary market economy}

In a market economy, each individual maximizes her/his utility (2) subject to the feasibility constraint (3). Hence, the following first-order condition holds.

$$
\frac{1}{1+\theta} \frac{\partial u}{\partial c_{t}}+\frac{\partial u}{\partial e_{t}}=0, \quad \forall t
$$

The dynamics of the market economy is fully described by two difference equations: (1) and (5).

For simplicity, we assume that the economy is initially located at some stationary state $\left(c^{*}, e^{*}\right)$. Then, it is clear from Figure 1 that the optimal tax rate $\theta^{*}$ in the stationary state $E^{*}$ is $\frac{\alpha}{1-\alpha}$.

\section{Optimal social planning and utility discounting}

We now focus on the social planning problem under an ordinal utilitarian-egalitarian definition of sustainability. ${ }^{\mathrm{f}}$ Namely, we have the following.

\section{Definition 1 An economy is sustainable iff}

$$
u\left(c_{t}, e_{t}\right) \geq \bar{U}, \quad \forall t
$$

holds for some given $\bar{U}$. 
With this definition, we can express the maximization problem of the government as follows:

$$
\max _{\left\{c_{t}, e_{t}\right\}_{t=0}^{T}} u\left(c_{0}, e_{0}\right), \quad \text { s.t. } e_{-1}=\bar{e}, \quad u\left(c_{t}, e_{t}\right) \geq \bar{U} \quad \forall t .
$$

The corresponding Lagrangean $L$ is

$$
L \equiv u\left(e_{0}-\alpha e_{-1}, e_{0}\right)+\sum_{t=1}^{T} \lambda_{t}\left[u\left(e_{t}-\alpha e_{t-1}, e_{t}\right)-\bar{U}\right]
$$

The first-order condition yields

$$
\lambda_{t}\left[\frac{\partial u}{\partial c_{t}}+\frac{\partial u}{\partial e_{t}}\right]-\alpha \lambda_{t+1} \frac{\partial u}{\partial c_{t+1}}=0
$$

Note that the constraints (6) always bind at the point of the optimal plan $\left(c_{t}, e_{t}^{*}\right)$. That is,

$$
u\left(c_{t}^{*}, e_{t}^{*}\right)=\bar{U}, \quad \forall t
$$

This property can easily be shown as follows: By the Kuhn-Tucker theorem, the necessary-sufficient condition in a convex environment is to find the saddle point of the Lagrangean, and thus

$$
L\left(c, e, \lambda^{*}\right) \leq L\left(c^{*}, e^{*}, \lambda^{*}\right) \leq L\left(c^{*}, e^{*}, \lambda\right)
$$

holds. $(c, e, \lambda)$ is the $T+1$ dimensional vector of consumption, $\mathrm{CO}_{2}$ emission, and the Lagrangean multiplier. *indicates optimal values.

From the right-half of inequality (11),

$$
\left[\lambda-\lambda^{*}\right] \cdot\left[u\left(c^{*}, e^{*}\right)-\bar{U}\right] \geq 0, \quad \forall \lambda \geq 0
$$

must hold. Here denotes the inner product. Since we can select $\lambda$ to be smaller than $\lambda^{*},(10)$ must hold for inequality (12) to hold. ${ }^{\text {g }}$

An important property of the stationary state emerges in (9). The stream of Lagrangean multipliers, $\left\{\lambda_{t}\right\}_{t=1}{ }^{T}$, satisfies the following difference equation:

$$
\begin{aligned}
\lambda_{t}^{*}\left[1-\left[-\frac{\frac{\partial u}{\partial e^{*}}}{\frac{\partial u}{\partial c^{*}}}\right]\right] & =\alpha \lambda_{t+1}^{*} \Leftrightarrow \lambda_{t+1}^{*} \\
& =\frac{1}{\alpha}\left[1-\left[-\frac{\frac{\partial u}{\partial e^{*}}}{\frac{\partial u}{\partial c^{*}}}\right]\right] \cdot \lambda_{t}^{*}, \quad \lambda_{0}^{*}=1,
\end{aligned}
$$

where $\left(c^{*}, e^{*}\right)$ is a stationary state of equation (1) and $-\frac{\frac{\partial u}{\partial e^{*}}}{\frac{\partial u}{\partial c^{*}}}$ is the marginal rate of substitution between consumption and the stock of $\mathrm{CO}_{2}$ in the stationary state.

Using the method of Negishi (1960), we can easily prove that the maximization problem (8) with the initial condition, $e_{-1}=e^{*}$, is equivalent to the maximization of the following social welfare function:

$$
\max _{e_{t}} S W \equiv \max _{e_{t}} \sum_{t=0}^{T} \lambda_{t}^{*} u\left(e_{t}-\alpha e_{t-1}, e_{t}\right), \quad e_{-1}=e^{*}
$$

Thus, the endogenously determined Lagrangean multipliers $\left\{\lambda_{t}\right\}_{t \geq 0}$ correspond to the optimal social discount rates. ${ }^{\mathrm{h}}$

The first-order condition of (14) in the steady state is

$$
\frac{\partial S W}{\partial e_{t}}=\left[\lambda_{t}^{*}-\alpha \lambda_{t+1}^{*}\right] \frac{\partial u}{\partial c^{*}}+\lambda_{t}^{*} \frac{\partial u}{\partial e^{*}}=0 .
$$

It is clear from (13) that such conditions are satisfied due to the definition of $\left\{\lambda_{t}{ }^{*}\right\}_{t \geq 0}$.

It is also clear from (13) that utility discounting is permitted only when

$$
\frac{\lambda_{t+1}^{*}}{\lambda_{t}^{*}}<1 \Leftrightarrow 1-\alpha=\frac{1}{1+\theta^{*}}<-\frac{\frac{\partial u}{\partial e^{*}}}{\frac{\partial u}{\partial c^{*}}} .
$$

Whenever the same allocation is also attained by a market economy, (5) will hold. Consequently, the necessary and sufficient condition for permitting discountingprogramming is

$$
\frac{1}{1+\theta}>\frac{1}{1+\theta^{*}} \Leftrightarrow \theta^{*}>\theta
$$

where $\theta$ is the existing carbon tax rate. That is, the social programming with discounting corresponds to lowering the proportional tax to a level lower than that in the market economy optimum. Such a steady state is illustrated by point $E_{S}$ in Figure 1 . This implies that utilitydiscounting social programming leads to excess emissions of $\mathrm{CO}_{2}$, even from the ordinal utilitarian viewpoint. To sum up, we have the following theorem.

Theorem 1 As long as the economy is sustainable, the weight of each generation's utility in the social welfare function should be allotted equally in a planning economy. Utility discounting corresponds to the carbon tax rate being lower than the optimum in a market economy. That is,

$$
\lambda_{t}^{*} \leq 1 \quad \forall t \quad \Leftrightarrow \quad \theta \leq \theta^{*}=\frac{\alpha}{1-\alpha}
$$

holds with equality only when $\lambda_{t}{ }^{*}=1$.

\section{Sustainability and discounting}

In this subsection, we deal with the relationship between the sustainable utility $\bar{U}_{j}$ and utility discounting.

We have the following representation that is equivalent to Theorem 1. 
Theorem 2 The social welfare function (14) is maximized when the Lagrangean (8) evaluated at the optimal solution is maximized on the feasible sustainable utility level $\bar{U}{ }^{\mathrm{i}}$

\section{Proof.}

According to Theorem 1, applying the optimal carbon tax rate $\theta^{*}$ to a market economy is equivalent to setting the discount rate as zero in the social welfare function. Hence, we can sufficiently prove the theorem by showing that maximizing the Lagrangean evaluated at the optimal solution concerning feasible sustainable utility level $\bar{U}$ is equivalent to applying the optimal tax rate $\theta^{*}=\frac{\alpha}{1-\alpha}$.

The Lagrangean evaluated at the optimal solution $L^{\prime \prime}$ is

$$
L^{*}(\bar{U})=u\left(c_{t}^{*}(\bar{U}), e_{t}^{*}(\bar{U})\right),
$$

where * indicates optimal values. Since all constraints are binding for the optimal solution, all terms of the Lagrangean after the current period $t$ vanish.

Differentiating (16), we obtain

$$
\begin{aligned}
\frac{d L^{*}}{d \bar{U}} & =\frac{\partial u}{\partial c} \frac{d c_{t}^{*}}{d \bar{U}}+\frac{\partial u}{\partial e} \frac{d e_{t}^{*}}{d \bar{U}} \\
& =\left[1-\frac{\frac{\partial u}{\partial e_{t}^{*}} \frac{d e_{t}^{*}}{d u} \frac{\bar{U}}{d c_{t}^{*}}}{\partial c_{t}^{*}} \frac{\partial u}{d \bar{U}}\right] \frac{d c_{t}^{*}}{\partial \bar{U}} \\
& =\left[1-\frac{\partial u}{\frac{\partial e_{t}^{*}}{\partial u}} \frac{d e_{t}^{*}}{\partial c_{t}^{*}}\right] \frac{\partial u}{\partial c} \frac{d c_{t}^{*}}{d \bar{U}}
\end{aligned}
$$

From (3), it is clear that $\frac{d e_{t}^{*}}{d c_{t}^{*}}=\frac{1}{1-\alpha}$ in the stationary state. Hence (17) can be rewritten as

$$
\frac{d L^{*}}{d \bar{U}}=\left[1-\frac{1}{1-\alpha} \frac{\frac{\partial u}{\partial e_{t}^{*}}}{\partial u} c_{t}^{*}\right] \frac{\partial u}{\partial c} \frac{d c_{t}^{*}}{d \bar{U}}
$$

The optimal solutions satisfy (5). Furthermore, it is clear from Figure 1 that

$$
\begin{aligned}
\frac{d c_{t}^{*}}{d \bar{U}}<0, \quad \text { if } \frac{\frac{\partial u}{\partial e_{t}^{*}}}{\frac{\partial u}{\partial c_{t}^{*}}}>\frac{1}{1+\theta^{*}}, \text { and } \frac{d c_{t}^{*}}{d \bar{U}} \\
>0, \quad \text { if } \frac{\frac{\partial u}{\partial e_{t}^{*}}}{\frac{\partial u}{\partial c_{t}^{*}}}<\frac{1}{1+\theta^{*}} .
\end{aligned}
$$

Thus, this gives Figure 2. We can clearly see that (16) is maximized at

$$
\frac{\frac{\partial u}{\partial e_{t}^{*}}}{\frac{\partial u}{\partial c_{t}^{*}}}=\frac{1}{1+\theta^{*}} .
$$

Accordingly, $L^{\prime \prime}$ is maximized on $\bar{U}$ when a market economy adopts the optimal carbon tax rate $\theta^{*}$.

Since Theorem 2 implies that

$$
\bar{U}^{*}=u\left(c^{*}\left(\bar{U}^{*}\right), e^{*}\left(\bar{U}^{*}\right)\right), \bar{U}^{*} \equiv \arg \max _{\bar{U}} u\left(c^{*}(\bar{U}), e^{*}(\bar{U})\right),
$$

in principle, there is no conflict between generations regarding the optimal carbon taxation. Equation (19) indicates that the optimal social planning by the current generation is also optimal from the viewpoint of future generations. In this sense, the social planning is time consistent, and hence, the utility level required for sustainability is set at the most desired level (see Figure 1). ${ }^{j}$

\section{Infinite horizon case}

Finally, we discuss the case of an infinite time horizon for the social planning. According to Theorem 1, equal weighting is not constrained to unity. As such, we set $\frac{1}{T}$ as the weight and take the limit $T \rightarrow+\infty$. Then, we have the social welfare function for the infinite horizon case:

$$
\lim _{T \rightarrow+\infty} \frac{1}{T} \sum_{t=0}^{T} u\left(c_{t}, e_{t}\right)
$$

Thus, the divergence problem for the sum of utility can be avoided, even if the social discount rate is unity. Dutta (1991), Broome (1992), and Cline (1992) apply this

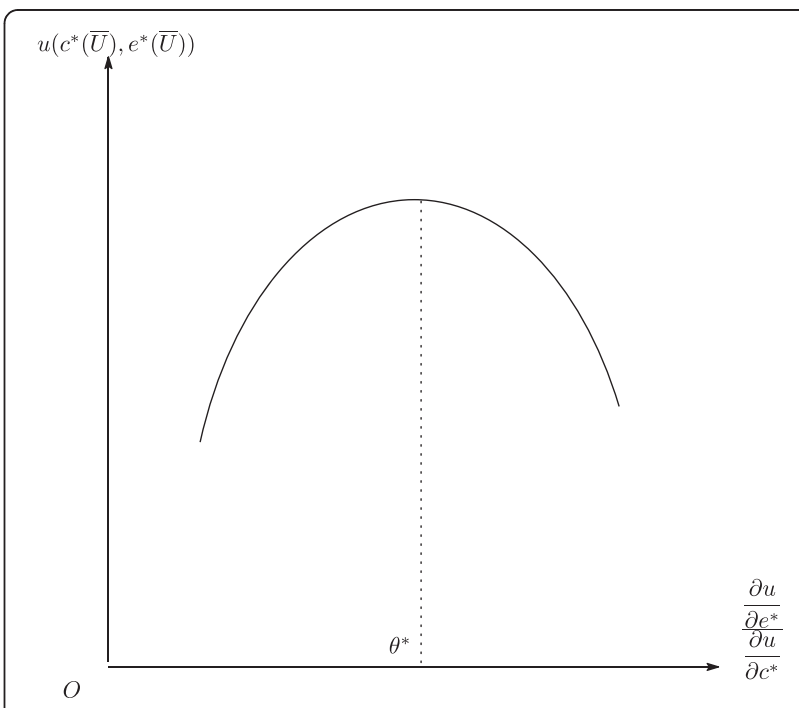

Figure 2 Time Consistency of the Optimal Planning. 
type of utility function to the global warming problem. Our paper provides a microeconomic foundation for their research, using Pareto efficiency and stationary equilibrium as a basis.

\section{Case Study: Second-best proportional carbon tax and the social discount rate}

In this section, as a case study, we calculate the relationship between the second-best carbon tax rate in a market economy and the corresponding social discount rate in a planning economy.

From equations (5) and (13), we obtain

$$
\frac{\lambda_{t+1}^{*}}{\lambda_{t}^{*}}=\frac{1}{\alpha}\left[1-\left[-\frac{\frac{\partial u}{\partial e^{*}}}{\frac{\partial u}{\partial c^{*}}}\right]\right]=\frac{1}{\alpha}\left[1-\frac{1}{1+\theta}\right] .
$$

The left-hand side of (21) is the second-best social discount rate $\operatorname{SDR}(\theta)$, which corresponds to the carbon tax rate $\theta$. We consider the length of one generation as approximately twenty years. Relying on Takahashi et al. (1980), we assume that emitted $\mathrm{CO}_{2}$ remains at a uniform 40 percent annually. That is, $\alpha$ is estimated as

$$
\alpha=\sum_{k=1}^{20} 0.4^{k}=\frac{0.4 \times\left[1-0.4^{20}\right]}{1-0.4} \approx .67
$$

Thus, we obtain Table 1.

This estimation is robust, as the calculation does not use any information concerning the utility function. In other words, any well-behaved utility function will obey equation (21). In addition, although the portion remaining $\alpha$ is probably underestimated, the tax rate corresponding to the endogenously determined social discount rate is never particularly low; hence, we should never be optimistic about the problem of $\mathrm{CO}_{2}$ emissions.

\section{Conclusions}

This paper analyzed the theoretical relationship between the social discount rate in a planning economy and the tax rate on $\mathrm{CO}_{2}$ emissions in a market economy. If a social planner discounts the utility of future generations, this corresponds to lowering the carbon tax rate below the optimum level in a market economy. Given the ordinal utilitarian view of

Table 1 The Social discount rate and the second-best proportional carbon tax rate

\begin{tabular}{llllllll}
\hline SDR & 1 & 0.99 & 0.98 & 0.97 & 0.96 & 0.95 & (per annum) \\
\hline$\lambda_{t+1}^{*}$ & 1 & 0.98 & 0.67 & 0.55 & 0.45 & 0.37 & (per twenty years) \\
\hline$\theta$ & 200 & 191 & 122 & 58 & 43 & 32 & $(\%)$ \\
\hline
\end{tabular}

sustainability, it is desirable to pay the true price of $\mathrm{CO}_{2}$, which is

$$
\alpha+\alpha^{2}+\cdots=\frac{\alpha}{1-\alpha} .
$$

This implies that a planner should not discount the utility of any generation in a centralized economy, and that the optimal tax rate must be equal to the total portion of $\mathrm{CO}_{2}$ remaining $\frac{\alpha}{1-\alpha}$ in a decentralized economy.

Finally, we must note that some important issues are not analyzed in this paper. First, as we concentrated on the properties of the stationary state, we have neglected the issues of the transition process. While such an analysis is beyond the analytical procedure used here, it would be worthwhile to try a numerical analysis or simulation to investigate how the optimal discount (possibly premium) rate varies through such adjustment periods.

Second, we have completely neglected the existence of uncertainty. Specifically, it is natural to assume that governments do not accumulate information reliable enough to determine how the $\mathrm{CO}_{2}$ emissions and economic activities correlate. This fact makes it very difficult to formulate the agreement necessary to introduce a proportional carbon tax. It also implies that governments tend to underestimate the optimal discount rate. The optimal decision under such uncertainty would be an important topic for future research.

\section{Methods}

The tradeoff between consumption utility and the disutility from the climate change which is summarized by the total stock of carbon dioxide is expressed by a utility function. Each generation enjoys consumption, but instead, emits carbon dioxide, and thus the concentration of carbon dioxide occurs. We calculate the optimal proportional carbon tax that prevents the excess emission by using only the information concerning the feasibility condition between consumption and emission independent of the form of utility function. The optimal social discount rates in a planning economy are calculated as the rates by which the economy can attain the same intergenerational resource allocation as that in a market economy where the optimal proportional carbon tax is adopted. We find such an endogenously determined optimal discount rate is zero.

\section{Endnotes}

${ }^{a}$ For example, see Dasgupta and Heal (1974), Hartwick (1977), and Solow (1986). Weitzman (1998) finds that the lowest discount rate should be applied to the fardistant future. However, he does not clarify why future projects per se should be discounted.

"We use the term "ordinal utilitarian" in the following sense. Ordinal utilitarian implies that an individual welfare is measured only by their consumption and $\mathrm{CO}_{2}$ 
level, which is considered a cause of global climate change, and assumes that the comparison of utilities between different individuals is not feasible.

${ }^{\mathrm{c}} \mathrm{We}$ never comment on whether a market economy or a planning economy is preferable for preventing excess emissions problem because both systems potentially give the best outcome. Our main interest is in investigating how the best outcome is attained by these alternative systems.

${ }^{d}$ Takahashi et al. (1980) consider two cases: First, the case that there is a homogenous $75 \mathrm{~m}$ thick surface layer, which is isolated from the underlying deep water. The other case deals with a $4000 \mathrm{~m}$ deep homogenous ocean. The former case shows that about $40 \%$ of emitted $\mathrm{CO}_{2}$ remains in the air although in the latter case only $2 \%$ of $\mathrm{CO}_{2}$ remains. Weiss (1974) deals with the issue of how the solubility of $\mathrm{CO}_{2}$ varies with salinity.

As Tanaka (1993) discusses, there is a serious problem of the 'missing sink' concerning the absorption of $\mathrm{CO}_{2}$. According to Houghton et al. (1990), a discrepancy exists in the emission/absorption of $\mathrm{CO}_{2}$ of the order of $1.6 \pm 1.4$ giga-ton. Since the emission from fossil fuel combusting is more accurately estimated at $5.4 \pm 0.5$ giga-ton, such a discrepancy cannot be neglected. Generally, the current absorption ability of oceans is estimated at $2.0 \pm 0.8$ giga-ton.

${ }^{\mathrm{e}}$ Note that although individuals know the values of $\theta$ and $\tau$, they do not consider the government's budget constraint relationship in their decision process. It never contradicts their rational economic behavior.

${ }^{\mathrm{f}}$ This definition of sustainability is identical to that in Pezzey (1997), although we do not regard there is contradiction between sustainability and "optimality" as Pezzey (1997) insists.

${ }^{\mathrm{g}}$ This concise proof is based on Uzawa's proof. For more details, see Uzawa (1958).

${ }^{\mathrm{h}}$ Negishi (1960) shows that the Pareto-efficient equilibrium in a market economy is equivalent to maximizing as if considering an additive-separable social utility function in a planning economy wherein the weight of each individual's utility is equal to his/her inverse of the marginal utility of income.

${ }^{\mathrm{i}}$ Note that whenever we predetermine the optimal social discount rate $\lambda^{\prime \prime}$, the minimum required utility $\bar{U}_{t}$ is determined to be consistent with the discount rate.

'Dasgupta and Heal (1974), Hartwick (1977), and Solow (1986) define sustainability as maintaining a constant consumption level over time. However, their definition of sustainability has an ambiguous welfare economics foundation. Arrow et al. (2003) define sustainability as a utility integral that increases over time. Besides the ambiguity in its welfare economics foundation, this utility integral analysis may lack the ability to deal with the conflict between generations easily.

\section{Competing interests}

The author declares that he has no competing interests.

\section{Author's contribution}

MO carried out the modeling and analyzed the model. He also collected data that are necessary for estimating the first and second best carbon-tax ratios and corresponding social discount rates and drafted the manuscript. All authors read and approved the final manuscript.

\section{Acknowledgement}

The author is thankful to Susumu Cato and anonymous reviewers for their constructive and incisive comments and suggestions.

Received: 25 July 2012 Accepted: 9 January 2013 Published: 16 January 2013

\section{References}

Arrow K, Dasgupta P, Mäler K-G (2003) Evaluating projects and assessing sustainable development in imperfect economies. Environ Resour Econ 26:647-685

Blackorby C, Bossert W, Donaldson D (1995) Intertemporal population ethics: Critical-level utilitarian principle. Econometrica 63:1303-1320

Broome J (1992) Counting the Cost of Global Warming. White House Press, London

Cline W (1992) The Economics of Global Warming. Institute for International Economics, Washington D.C

Cowen T (1992) Consequentialism implies a zero rate of intergenerational discount. In: Laslett P, Fishkin J (eds) Justice Between Age Groups and Generations. Yale University Press, New Haven

Dasgupta P (2008) Discounting climate change. J Risk Uncertain 37:141-169

Dasgupta P, Heal G (1974) The optimal depletion of exhaustible resources. Rev Econ Stud :3-28, Symposium

Diamond P (1965) The evaluation of infinite utility stream. Econometrica 33:170-177

Dutta P (1991) What do discounted optima converge to? J Econ Theory 55:64-94

Hartwick J (1977) Intergenerational equity and the investing rents from exhaustible resources. Am Econ Rev 67:972-974

Hulme M (2009) Why We Disagree about Climate Change: Understanding Controversy, Inaction and Opportunity. Cambridge University Press, Cambridge

Houghton J et al (1990) Climate Change. Intergovernmental Panel on Climate Change. Cambridge University Press, Cambridge, UK

Houghton J et al (1996) Climate Change 1995: The Science of Climate Change. Intergovernmental Panel on Climate Change, Working Group I. Cambridge University Press, Cambridge, UK

Koopmans T (1960) Stationary ordinal utility and impatience. Econometrica 28:286-309

Negishi T (1960) Welfare economics and existence of an equilibrium for a competitive economy. Metroeconomica 12:92-97

Pearson C (2000) Economics and the Global Environment. Cambridge University Press, Cambridge, UK

Pearson C, Pryor A (1994) Environment: North and South: An Economic Interpretation. John Wiley \& Sons, New York, USA

Pezzey J (1997) Sustainability constraints versus "optimality" versus intertemporal concern, and axiom versus data. Land Econ 73:448-466

Ramanathan V, Cicerone R, Singh H, Kiehl J (1985) Trace gas trends and their potential role in climate change. J Geophys Res 90:5547-5566

Solow R (1986) On the intergenerational allocation of natural resources. Scand J Econ 88:141-149

Takahashi T, Wallas B, Werner S (1980) Carbonate chemistry of the surface waters of the world oceans. In: Goldberg ED, Horibe Y, Saruhashi K (eds) Isotope Marine Chemistry. Uchida-Rokakuho, Tokyo, Japan

Tanaka M (1993) The mechanism of global warming (in Japanese). In: Uzawa H, Kuninori M (eds) Economic Analysis of Global Warming. University of Tokyo Press, Tokyo, Japan 
Uzawa H (1958) The Kuhn-Tucker theorem in concave programming. In: Arrow K, Hurwicz L, Uzawa H (eds) Studies in Linear and Non-Linear Programming. Stanford University Press, California

Uzawa H (2003) Economic Theory and Global Warming. Cambridge University Press, Cambridge, UK

Weiss RF (1974) Carbon dioxide in water and sea water: The solubility of a nonideal gas. Mar Chem 2:203-215

Weitzman M (1998) Why the far-distant future should be discounted at its lowest possible rate. J Environ Econ Manag 36:201-208

doi:10.1186/2193-2697-2-1

Cite this article as: Otaki: Endogenous social discount rate, proportional carbon tax, and sustainability: Do we have the right to discount future generations' utility?. Environmental Systems Research 2013 2:1.

\section{Submit your manuscript to a SpringerOpen ${ }^{\circ}$} journal and benefit from:

- Convenient online submission

- Rigorous peer review

- Immediate publication on acceptance

- Open access: articles freely available online

- High visibility within the field

- Retaining the copyright to your article

Submit your next manuscript at $>$ springeropen.com 